\title{
Modelos de Negócios na Área da Moda: Um Estudo Sobre Setores Tradicionais e Inovadores
}

\author{
Business Models in Fashion Area: A Study on Traditional and \\ Innovative Sectors
}

Cristiano Max Pereira Pinheiro
Doutor, Universidade Feevale
maxrs@feevale.br

Christine Bahia de Oliveira

Doutora, Universidade Feevale

Camilla Steinhaus

Bacharelanda, Universidade Feevale

Milena Cherutti

Bacharelanda, Universidade Feevale 


\title{
Modelos de Negócios na Área da Moda: Um Estudo Sobre Setores Tradicionais e Inovadores
}

Business Models in Fashion Area: A Study on Traditional and Innovative Sectors

Cristiano Max Pereira Pinheiro, Christine Bahia de Oliveira, Camilla Steinhaus, Milena Cherutti

\section{Resumo}

O atual mercado extremamente competitivo leva às empresas a procurarem melhores desempenhos, como também, formas de diferenciação e outras organizações. Levando em consideração que modelo de negócios consiste na organização de detalhes estratégicos e operacionais do empreendimento, a fim de destacar-se no mercado e separar os diferentes setores nos quais a indústria abrange, e que a moda é uma das maiores indústrias existentes no mercado, procurou-se estabelecer a definição de diferentes modelos de negócios nesta área, dividindo-os em dois grandes grupos: os tradicionais e os inovadores. Tal pesquisa visa apontar alguns setores de negócios no âmbito da moda, de forma simplificada e resumida, servindo como base para futuros trabalhos. O presente estudo resultou da falta de exploração da área, com o objetivo de reconhecer e explorar 0 funcionamento de alguns modelos de negócios.

Palavras-chave: Modelos de negócios, Inovação, Economia criativa

\begin{abstract}
The current highly competitive market leads companies to seek better performances, but also other forms of differentiation and organization. Assuming business model is how to organize strategic and operational details of the enterprise, in order to stand out in the market and separate the different sectors in which the industry covers, and fashion as one of the biggest industries in the market, we tried to establish the definition of different business models in this area, dividing them into two major groups: the traditional and the innovative. This research aims to point out some business sectors within the fashion, in a simplified and summarized form, serving as a basis for future works. The present study resulted from the lack of exploration of the area, in order to recognize and explore the operation of some business models.
\end{abstract}

Keywords: Business models, Innovation, Creative economy 


\section{Introdução}

O atual mundo globalizado e competitivo demanda estratégias diferenciadas para as empresas conseguirem se manter no mercado, considerando que as exigências aumentam cada vez mais. Há uma grande preocupação em satisfazer consumidores que procuram maior qualidade e variedade de produtos, com preços mais acessíveis, contando com baixos custos de produção para assim, garantir boa lucratividade (Hornburg; Tubino; Ladeira; Thonern; Riffel, 2008). Tamanha competitividade faz com que empresas procurem mudanças que promovam desempenhos melhores para aumentar as inovações e atratividades dos negócios.

Portanto, o presente trabalho delineou o mapeamento de alguns modelos de negócios existentes no mercado da moda, subdivididos em dois grandes grupos: os modelos tradicionais, formado por aqueles cujo modelo de negócios já é conhecido pelo grande público, mantendo-se há muitos anos no mercado, o qual, no presente trabalho, é composto pelas categorias Criação (estilista), Consultoria de moda, Indústria/produção, Indústria têxtil, Jornalismo em moda, Maisons (produtos de luxo), Marketing em moda, Modelista, Produção de moda, Varejo e Vitrinista; e os modelos inovadores, formado por modelos de negócios relativamente novos, que utilizam tecnologia diferenciada, e que tornaram-se prática conhecida pelos consumidores somente nos últimos anos, composto aqui por Assessoria de branding para empresa, Blog de moda, Customização, Ecomoda, E-commerce e Fast fashion. O objetivo de tal pesquisa se dá pela falta de exploração da área, visando reconhecer e mapear o funcionamento de alguns modelos de negócios.

Tal área de conhecimento foi escolhida, devido a sua grande importância no cenário econômico atual do país, já que, dentre as dez profissões criativas mais numerosas na Indústria de Transformação, o setor da moda está em terceiro lugar, empregando em torno de 16,1 milhares de artesãos de calçados e artefatos de couros e peles, em sétimo lugar, com aproximadamente 6,8 milhares de artesãos de metais preciosos e semipreciosos, como também, 6,7 milhares de modelistas de roupas ocupam o oitavo lugar da tabela (Firjan, 2014) e o Brasil está em quinto lugar dentro dos países que mais consomem roupas (Sebrae, 2013).

Desse modo, organizou-se o trabalho de forma que, primeiramente, foi conduzida a Introdução e, logo após, há a segunda seção, onde define-se os Modelos de Negócios, seguido da terceira seção com as definições constatadas 
sobre Moda. Durante a pesquisa, são usados como referência autores como Blythe, Callan, Farias, Bergamo, et al, a fim de edificar certos conceitos. A quarta seção deste trabalho é composta pelos modelos de negócios existentes na área da moda, subdivi dos em dois grandes grupos: tradicionais e inovadores. Então, ao finalizar este trabalho, são descritas as considerações finais e as referências utilizadas no decorrer da pesquisa.

Adiante segue a segunda seção, abrangendo definições de Modelo de Negócios.

\section{Modelo de negócios}

Existem contradições entre os conceitos de modelo de negócios, da mesma forma, é muito comum a falta de discernimento entre modelos de negócios, plano de negócios e estratégia, em especial a associação direta entre modelos de negócios e estratégia. Assim, o objetivo desta sessão é conceituar tais termos a fim de entender suas reais funções e importância para este estudo.

Para contribuir no esclarecimento da questão apresentada no parágrafo anterior, é preciso, primeiramente, comparar os conceitos de modelo de negócios e planos de negócios, uma vez que este refere-se a um documento que contém detalhes estratégicos e operacionais do negócio, visando mostrar a outras pessoas que uma determinada ideia é factível (Honig e Karlsson, 2004). Tais detalhamentos podem ser obtidos através do planejamento estratégico ou mesmo do modelo de negócios, tornando o plano um "repositório destas informações, com formatação sucinta e clara o suficiente para ser utilizada em busca de investimentos ou para circular pelos diferentes níveis organizacionais em caráter informativo" (Foo, Wong e Ong, 2004). Assim, o plano de negócios visa comunicar internamente, aos colaboradores, e externamente, aos parceiros de negócio, quais são os objetivos da iniciativa e buscar financiamento para ela, diferindo assim do conceito de modelo de negócios, elucidado no parágrafo seguinte.

O modelo de negócios embasa-se em uma configuração na qual uma empresa "cria valor para todos os seus principais públicos de interesse". Da mesma maneira, o aproveitamento de tal método define uma arquitetura "estruturada e unificada", o que ajuda a perceber "os diversos elementos que compõem todas as 
formas de negócio", e admitindo a definição do termo modelo de negócios como a primeira etapa para obter sucesso em um empreendimento (Sebrae, 2014).

Chesbrough e Rosenbloom (2002, p. 533), definem modelo de negócios como "a descrição de como a organização pretende criar valor no mercado", o que inclui uma combinação de produtos, serviços, imagem e distribuição única, bem como o que está sob a organização de pessoas e a infraestrutura operacional para realizar o seu trabalho. Seguindo a visão dos autores, Timmers (1998) complementa, afirmando que "um modelo de negócios é a organização ou arquitetura de produtos, serviços e fluxos de informação, e as fontes de recursos e benefícios para fornecedores e clientes".

Lee (2001), caracteriza modelo de negócios como sendo "a totalidade de como uma companhia define a seleção de seus clientes e os diferenciais de sua oferta", definindo as atividades que darão performance a si mesma e o que será terceirizado; configura seus recursos, vai ao mercado, cria utilidade aos consumidores e captura lucro, ou seja, todo sistema para entregar utilidade para os clientes obtendo lucro.

Pode-se dizer então que modelo de negócios é o primeiro determinante da performance de uma empresa (Afuah e Tucci, 2001), sendo o método adotado afim de criar valor através dos produtos e serviços que oferece, da sua estrutura organizacional, da alocação de recursos, e de seus processos de interação com parceiros e clientes, visando a criação de diferenciais e a sustentabilidade.

Sobre a confusão entre os termos modelo de negócios e estratégia, entende-se que modelo de negócios é somente uma das ferramentas estratégicas utilizada para criação de valor de produtos ou serviços de determinada organização.

\footnotetext{
Estratégia é mais amplo que modelo de negócios, porque é parte da estratégia a própria revisão dos modelos de negócios. De fato, um movimento estratégico de uma organização pode ser o abandono de um modelo de negócios ou a adoção de um novo. Quando falamos de grandes corporações, a orquestração de diferentes modelos de negócios para a geração de valor para a organização como um todo faz parte do plano estratégico dessa corporação. (Andrade, 2001, p.34)
}

Linder e Cantrell (2001, p.34) também esclarecem as diferenças entre os dois termos, desfazendo o mito de que modelos de negócios só se aplicam a empresas "ponto-com"1, enquanto as empresas tradicionais utilizam estratégia, e 
defendem ainda que modelo de negócios não é substituto para a estratégia, já que a estratégia abarca as aspirações de realizações da empresa, e o modelo de negócios visa operacionalizar essas aspirações.

Consoante Afuah e Tucci (2001), um modelo de negócios bem formulado e alinhado ao mercado irá render lucros maiores do que os competidores. Desta forma, novos produtos demandam novas estratégias de atuação e novos modelos de negócios, a fim de que seja possível compreender o mercado de atuação e explorá-lo adequadamente.

Para manter-se estável no mercado, todos os modelos de negócios necessitam de estratégias e formas de como adquirir valor ao produto. O setor da moda - que identifica-se pela prestação de serviço - admite como estratégia a segmentação, a fim de definir o produto a ser vendido, oferecer serviços e diferenciais adequados ao público alvo, usar através do marketing a divulgação dos serviços e criar uma identificação com o consumidor, com o propósito de torna-lo cliente.

Da mesma forma, o setor da moda trabalha com a criação de marcas, sejam elas vinculadas ao nome do próprio criador, ou algo relacionado ao serviço a ser prestado. As marcas agem de forma que registram no consciente do consumidor os "valores tangíveis e no inconsciente, os valores intangíveis", registrando também, "as emoções que estão ligadas a elas" (Costa; Contarin; Diniz, 2009, p.32), de forma que a criação de estratégias, junto com planejamentos, serve como um caminho a ser seguido.

Agora que modelo de negócios se tornou mais claro, vamos focar na moda e como estes modelos podem estar inseridos nesta área.

\section{Moda}

A moda consiste em uma abrangente indústria, que admite vários setores, desde estilistas que participam da criação, modelistas, costureiras até chegar o produto pronto em mãos às lojas, onde os consumidores tem contato com a peça. Sem mencionar, também, os profissionais que trabalham nas áreas de jornalismo, assessoria, marketing, produtor e blogs de moda. 
Assim, pode-se entender a grande influência que a moda exerce na satisfação individual e no poder de interação dos indivíduos. E uma das formas mais comuns por meio da qual as pessoas entram em contato com a moda é o vestuário, que é uma das suas facetas mais visíveis. O processo de escolha, compra e uso do vestuário pode ser extremamente aprazível e traz inúmeras contribuições ao bem-estar da pessoa que o vivencia. Além disso, é importante referir que é um sistema que no seu todo está conectado a questões psicológicas e sociológicas, em virtude das sensações de prazer e satisfação que proporciona, e também à sensação de inclusão, por possibilitar que a pessoa faça parte de um grupo que compartilha dos mesmos gostos e estilos. Daí ter se criado a expressão "experiência do vestuário", por meio da qual os indivíduos podem experimentar a satisfação de se vestirem como o desejado, de acordo com suas mais íntimas intenções (Woltz; Carvalho, 2008, p. 3).

O ciclo de moda tal qual conhecemos atualmente, deu-se a partir da Segunda Guerra Mundial, com o crescimento do capitalismo e o início do comércio de roupas já prontas, por meio da criação do termo em francês prêt-à-porter, que em português se traduz à "pronto para vestir". A década de 60 admitiu significativa influência na construção de uma nova imagem da moda, devido a uma série transformações sociais ocorridas, sendo essa cultura absorvida e, muitas vezes, reelaborada para peças dos dias de hoje. Houve, também, uma "produção mais cuidadosa e atenta das imagens veiculadas nos editoriais e anúncios das revistas, que passaram a ter a função primordial de vender um produto" (Farias, 2011).

Segundo Matharu (2011), o tema começou a adquirir maior importância quando antropólogos, filósofos, psicólogos, sociólogos, teóricos e acadêmicos começaram a reproduzir estudos sobre o vestuário na cultura moderna. Além de citar que o nosso jeito de vestir admite manifestação da individualidade e liberdade de expressão, como também, associa grupos diferentes através de "ideias, gostos, origens, culturas religiões semelhantes".

Também se define a moda como uma manifestação artística das mudanças sociais, e uma expressão cuja definição não é precisa, assim como a roupa admite valor além da razão, um produto que surge especialmente da sensibilidade de um artista. A característica central das marcas de moda é "que todas comercializam a imagem de um estilo, ou seja, de um conjunto de atribuições que, na prática, se esforça por imprimir ao consumidor individual e ao mundo que o rodeia, e com o qual ele se identifica" (Bergamo, 1998).

O processo que consiste na criação de produtos de moda, implica na conscientização e aplicação de técnicas, pesquisas de mercado, materiais 
específicos e ter conhecimento do ciclo de vida do produto (Alencar, Boueri, 2013, p. 3-4). Os autores também citam que:

\begin{abstract}
O desenvolvimento desses novos produtos é um problema multifatorial e seu sucesso ou fracasso depende da análise de diversos fatores, como, por exemplo, necessidade dos consumidores, aceitação dos distribuidores, facilidade de fabricação, durabilidade e confiabilidade do produto. O objetivo do designer é encontrar uma solução do problema que possa ser transformada em um produto industrial e satisfaça as necessidades humanas da melhor forma possível (Alencar, Boueri, 2013, p. 3).
\end{abstract}

Kachba e Hatakeyama (2013) discorrem sobre como o fluxo de inovações tem aumentado nas áreas de design de produto e produção de marketing, e as empresas dedicam-se cada vez mais à moda, com um processo de design intensivo. Portanto, a moda e o design admitem grande vínculo, o qual define-se como uma conciliação entre satisfazer o cliente e adquirir lucros para seu empreendimento, onde é necessário, de forma inovadora, coerir cinco componentes básicos do design, tais como a performance, a qualidade, a durabilidade, a aparência e o custo dos produtos (Kotler, 1989).

Em 1998, foi reproduzido um mapeamento sobre as atividades criativas existentes no Reino Unido, pelo DCMS (Departamento de Cultura, Mídia e Esportes), no qual tinha por objetivo definir os setores que abrangeriam as indústrias criativas, e dentre eles, situa-se a área da moda (Blythe, 2001). Em vista disso, admite-se que a moda é uma grande contribuinte para a economia criativa, já que, segundo o Sebrae (2014) abrange os ciclos de criação, produção e distribuição de bens e serviços que usam criatividade e capital intelectual como insumos primários.

Um ambiente de criatividade, inovação e símbolos admite alternativas diferenciadas para a construção de uma cadeia produtiva complexa, na qual tal economia tem como objetivo impor valor a bens culturais "que se transformam em bem-estar individual e coletivo". Onde a economia criativa trabalha de forma que os ciclos de criação, produção, distribuição, difusão e fruição dos produtos produzidos através da criatividade proporcionam, além de desenvolvimento econômico, social e cultural também. Seus produtos são caracterizados pela sua dimensão simbólica (Sebrae, 2014).

A inovação e a diferenciação são reproduzidos através da prática de setores criativos, os quais admitem "origem na criatividade, na competência e talento 
individuais", de forma que assim, transformam a propriedade intelectual em riqueza e emprego (Fracaro, Paiva, Rosa, Bastos, 2012).

A sessão seguinte é composta pelos modelos de negócios existentes na área da moda, subdivididos em dois grandes grupos: tradicionais e inovadores.

\section{Modelos de negócio em moda}

\subsection{Tradicionais}

A primeira parte da quarta seção deste trabalho é composta por modelos tradicionais existentes na área da moda, ou seja, aqueles cujo modelo de negócios já é conhecido pelo grande público, mantendo-se há muitos anos no mercado.

\subsubsection{Criação (estilista)}

O trabalho do estilista não pode ser visto somente como a produção de roupas sob encomenda ou medida, muito menos que a sua única utilidade seria a criação de desenhos. Além dessas atribuições, o fashion designer admite como característica central a "capacidade de criar e projetar produtos novos", tendo como principal preocupação atingir as necessidades do consumidor (Keller, 2010). O autor cita, também, que o trabalho do estilista provém do intangível, ou seja, tem origem na produção criativa. E a criatividade, no setor de criação de roupas, consiste em "uma atividade de concepção e de desenvolvimento de novos produtos", os quais admitem valores de cunho econômico e também cultural.

Portanto, o processo de criação precisa produzir conforme a demanda de mercado exigida, considerando itens específicos de cada peça, como cores, comprimento, detalhes, acabamentos.

\subsubsection{Consultoria de moda}

O consultor de moda pode tanto trabalhar em empresas - dando palestras sobre moda e estilo aos clientes e funcionários ou criando uniformes como dando consultoria a uma pessoa - através de orientações relacionadas ao que se adequa melhor ao corpo da pessoa e questões particulares - criando assim, uma imagem do indivíduo a ser passado à sociedade.

Conforme o site Brasil Profissões², tal profissional admite conhecimento das tendências a nível mundial, a fim de orientar seus clientes sobre moda, cores, 
estilo, tecidos, silhuetas. O consultor alia as tendências de moda, as traduzindo ao estilo da pessoa, expressando sua personalidade de forma com que se seu cliente sinta-se mais seguro.

\subsubsection{Indústria de confecção}

Uma das principais indústrias no setor da moda, juntamente com a indústria têxtil, consiste na indústria de confecção. Ela admite diversas fases, entre elas a parte de criação, construção das modelagens, risco e corte dos tecidos, costura das peças, acabamento e revisão. Após serem cortadas, as peças são separadas e organizadas de forma a facilitar o processo da costura, que consiste em certa de 50\% dos trabalhadores de uma empresa de confecção (Garcia, 2006).

No setor da costura, cada costureira é especializada em uma função, costurando apenas a parte que lhe é destinada, até a conclusão da peça. Então, são feitos os acabamentos necessários, como bainhas e decotes, e todas as peças são inspecionadas a fim de nenhum erro passar despercebido. Seguindo pesquisas da ABIT $^{3}$ (Associação Brasileira da Indústria Têxtil e de Confecção) a produção de artigos confeccionados aumento certa de $34 \%$ nos últimos dez anos, e no ano de 2010 era o quarto maior produtor a nível mundial, o que consiste em $2,8 \%$.

\subsubsection{Indústria têxtil}

A produção têxtil e de confecções foi uma das mais importantes na passagem da manufatura para os processos industriais. Atualmente, as indústrias têxteis e de vestuário constituem a quarta maior atividade econômica, concentram $5,7 \%$ da produção manufatureira e, segundo dados de 2011, abriga 1.6 bilhão de postos de trabalho, o equivalente a $16,2 \%$ do total de trabalhadores alocados na produção industrial. Segundo dados do Ministério de Desenvolvimento, Indústria e Comércio exterior (MDIC), o setor têxtil é o segundo maior gerador do primeiro emprego, e o segundo maior empregador da indústria de transformação.

Apesar de um dos maiores produtores têxteis do mundo, o Brasil apresenta dificuldades para desenvolver o setor. Os níveis de importação de países como China e Estados Unidos atingem números recordes, o que soma-se às condições de trabalho ao longo da cadeia produtiva, a necessidade de investimentos em inovação e novas tecnologias, a carga tributária e a qualificação da mão de obra, 
o crescimento do fast-fashion, entre outros, indicam que a indústria têxtil e de confecções brasileira caminha em direção a um novo momento. O segmento enfrenta ainda a limitação dos recursos naturais, pressão por métodos de produção mais eficientes e menos custosos e uma demanda de consumo crescente que exige preço, design, moda, e que, gradativamente, incorpora outros critérios no momento da compra, como qualidade, durabilidade e condições dignas de trabalho.

\subsubsection{Jornalismo de moda}

O jornalismo consiste em um processo de construção de informações que interfere em diversos fatores da vida cotidiana, conforme os veículos de comunicação. No âmbito da moda, a maneira como as matérias são representadas que confere novos significados às coleções e estilistas existentes. O jornalismo na moda, admite a criação de novas identidades, tanto sociais quanto culturais, através de escolhas diferenciadas de edições de fotos e textos, que contém significado (Hinerasky, 2006).

Tanto o jornalismo, como a moda estão diretamente ligados à novidade, 0 que faz com que a união dos dois traga sempre coisas novas, tornado cada vez mais interessante aos olhos do leitor. Uma das formas mais expressivas de tal modelo são os editoriais das revistas, onde a combinação de fatores como o cenário, produções, modelos com postura correspondendo ao visual ideal. Eles funcionam também como uma forma de comunicação com o público, "como a conjugação de todas as tendências e dá ao consumidor um tipo de informação, pasteurizada ou não, que indica como as peças devem ser combinadas, e a função disso" (Mendonça, 2013).

\subsubsection{Maisons (produtos de luxo)}

Os produtos considerados de luxo, são raros e distintos, atribui-se valor bastante elevado a tal devido à sua exclusividade, trabalho produzido normalmente com costura e bordados feitos à mão - e principalmente pelo nome que as grandes marcas sustentam. As maisons admitem um significado muito maior do que apenas negócios de moda, mas um símbolo da marca e sua forma de difundir aprendizados.

Consoante Geargeoura e Moriguchi (2011), tal negócio valoriza a tradição/histórico ligado ao fundador, tornando-se também, parte de cultura. A 
maison admite uma "multiplicidade de funções", onde a loja, o atelier de produção e a sede de negócios normalmente situa-se no mesmo espaço físico. Não obstante, a palavra maison tem origem francesa - já que os primeiros estilistas de luxo "nasceram" na França - e traduzida ao português significa casa.

\subsubsection{Marketing em moda}

O marketing atua de forma que, com técnicas e metodologias diferenciadas, admite uma identidade à marca, a qual será apresentada aos consumidores. Ele consiste em uma forma de se diferenciar no atual comércio competitivo, criando estratégias de distinção para a empresa, as quais consistem em agregar uma necessidade de consumo dos produtos. Tal necessidade se mostra presente na moda "como sistema de renovação constante", que consiste na ideia de necessidade de comunicação através do vestuário, o que resulta no consumo (Leães, 2008).

As estratégias de marketing admitem cada vez mais importância no mundo da moda, já que elas atribuem às marcas um significado, como uma "alma da marca". Certa característica contribui para o discernimento da marca, e mostrar que a mesma tem os produtos necessários a fim de suprir as necessidades dos consumidores. O marketing, juntamente com a moda, possui a intenção de atingir as expectativas para o consumo, considerando a importância de adquirir conhecimentos sobre a vida, os desejos e os gostos do público-alvo. Como também, o marketing pode ser definido como o canal que liga as empresas ao mercado.

\subsubsection{Modelista}

O modelista consiste no profissional encarregado de construir os moldes das peças de roupa a serem cortadas posteriormente. Segundo Rosa (2009), a modelagem tem por finalidade produzir a estrutura da roupa, através de técnicas que valorizam formas, volumes e caimentos conforme o desenho projetado pelo estilista. Ela compreende uma das partes iniciais do processo de criação e fundamental para a sustentação da marca.

Existem três técnicas diferencias de modelagem, a plana manual traçada no papel, com o auxílio de réguas e esquadros - a tridimensional ou moulage - onde modela-se o tecido em um modelo vivo ou manequim - e a plana informatizada - feita com o auxílio de softwares. 


\title{
4.1.9 Produção de moda
}

O produtor de moda providencia os meios que podem fazer a roupa planejada pelo estilista ser almejada pelos consumidores. Ele alia o estilo da marca ao que o consumidor gostaria de ver e vestir, através de desfiles, editoriais de revistas, propagandas e eventos, admitindo a função de transformar o desejo da marca em uma imagem a ser passada ao público, segundo um roteiro préestabelecido e com o intuito de reproduzir os padrões de beleza. Segundo o site da Pontifícia Universidade Católica do Rio de Janeiro (PUC-RIO) ${ }^{4}$, é importante que tal profissional tenha domínio das tendências de moda, estratégias para apresentação dos produtos e especialistas de cada tipo de trabalho necessário, como também deve ser organizado de acordo com suas tarefas e ágil para solucionar problemas recorrentes.

\subsubsection{Varejo}

O mercado do varejo de moda baseia-se na forma de oferta e procura onde um produto está a disposição do consumidor, nos mais distintos segmentos. Apresenta crescimento constante no cenário mundial, impulsionado pelo acirramento da competitividade entre as empresas e um público consumidor cada vez mais exigente.

\begin{abstract}
As três maiores populações consumidoras que participam do mercado varejista, hoje são: a Geração Pós - Guerra (de 37 aos 55 anos), a Geração $X$ (de 25 a 36 anos) e a Geração $Y$ (de 6 a 24 anos). Esses três segmentos não falam a mesma língua. A Geração Pós - Guerra responde a sinais de realização, status e desempenho; a Geração $X$ valoriza a imaginação, a criatividade e os relacionamentos, e a Geração $Y$ responde ao divertimento, á interatividade e às experiências (Gobé, 2002:43).
\end{abstract}

Assim, as organizações buscam um diferencial para se destacar em meio a este panorama, utilizando artifícios visuais, ou seja, na forma como o produto é exibido, com arranjos físicos de layout bem projetados, e artifícios emocionais, associando à essência do produto a emoção que existe no imaginário coletivo (Martins, 1999; Kapferer, 2004).

\subsubsection{Vitrinista}

A apresentação externa da loja determina a primeira impressão que o cliente tem do ponto de vendas, influenciando sua percepção quanto a qualidade, estilo e padrão de loja (Berman e Evans, 1998). A técnica do vitrinismo tem a função 
de projetar para o cliente uma imagem que facilite o reconhecimento da marca (Mason, Mayer, Wilkinson, 1993), fornecendo insumos para que haja uma maior conversação com este consumidor. Assim, é exigido do profissional um estudo prévio acerca da necessidade de marketing da empresa e um profundo entendimento sobre o público que consome a marca, pois estes indicarão a técnica vitrinista a ser utilizada.

\subsection{Inovadores}

A segunda parte da quarta seção deste trabalho é composta por modelos inovadores existentes na área da moda, ou seja, composto por modelos de negócios relativamente novos, que utilizam tecnologia diferenciada, e que tornaram-se prática conhecida pelos consumidores somente nos últimos anos,

\subsubsection{Assessoria de branding}

Um dos maiores focos de atuais estudos tem sido o valor das marcas. Elas são consideradas uma estratégia a fim de obter diferenciação de mercado, quando vinculadas ao auxilio das assessorias de branding (Luindía, 2001). Portanto, a assessoria de branding consiste na atuação de profissionais que praticam a promoção das marcas, através de publicações e entrevistas em sites, jornais e revistas, divulgação das ações e dos produtos produzidos pela empresa.

Segundo Melo (2009), a atribuição de valor às marcas demanda tempo e investimentos, considerando que a divulgação dos produtos pode aumentar a percepção dos consumidores com relação a marcas. Tal investimento admite um certo retorno para as empresas, em vista disso, os assessores de branding $^{5}$ tem sido cada vez mais procurados.

\subsubsection{Blog de moda}

Os blogs de moda podem ser considerados como um diário, onde o autor escreve sobre as coisas que gosta, faz, estuda, vivencia, etc. A maioria dos blogs admite em comum, informações sobre o autor e os conteúdos abrangentes do blog, espaço para comentários dos leitores e uma coluna com blogs que o autor recomenda. Os blogs são uma ferramenta de acesso livre, sem restrições, que 
admite possibilidade de uma comunicação aberta, e também informa a data e a hora das postagens (Gobbi, Benetti, 2012).

Tavernari e Murakami (2012) admitem que através do blogs de moda, e com a ajuda de diversas ferramentas, "meninas comuns têm a possibilidade de transformarem-se em curadoras, críticas, jornalistas, stylists e trendsetters do mundo fashion". As blogueiras são detentoras de informações privilegiadas, pois estão sempre junto com jornalistas e especialistas nas semanas de moda e eventos importantes ao redor do mundo, o que acarreta em maior rapidez dessas informações chegarem aos leitores, considerando que são instantaneamente postadas em suas redes sociais e logo viram pauto dos blogs.

\subsubsection{Customização}

A customização de roupas consiste em modificar peças prontas, utilizando diversas técnicas, a fim de torna-las exclusivas. Ela implica em bordados, tingimentos, cortes, costuras e aplicações utilizados de forma criativa e diferente. Segundo o Portal Educação (2013), a técnica de customização teria surgido nos anos 1960, através do movimento hippie, no qual seus integrantes tingiam e modificavam suas roupas de forma artesanal, gerando uma certa personalização do seu vestuário.

Diversos blogs e sites foram criados com o objetivo de ensinar as técnicas passo-a-passo, assim elas podem ser feitas pelas pessoas interessadas em casa. A customização também teve grande influência no hábito de comprar roupas em brechós, para depois serem adaptadas e "renovadas" de acordo com os gostos e preferências. As peças mais utilizadas a fins de customização consistem em camisetas, shorts e calças jeans, vestidos e jaquetas.

\subsubsection{Ecomoda}

A ecomoda não se trata apenas de uma moda, mas sim, demonstra a preocupação com a situação atual do planeta. A indústria têxtil consiste em um setor que causa grande poluição, como o uso em grande escala de agrotóxicos nas plantações de algodão, alteração na composição da água, entre outros. Portanto, a fim de diminuir tais danos, há uma nova geração de estilistas criando produtos sustentáveis, baseados em materiais reciclados e com propostas ecológicas 
Simples inovações na produção dos produtos diminuem consideravelmente, ou até mesmo podem eliminar totalmente os custos ambientais, considerando formas ecologicamente ecológicas, que originam em "novas possibilidades de mercados com os subprodutos obtidos através da reutilização dos resíduos do processo produtivo" (Santos, s.d.).

\subsubsection{E-commerce}

O e-commerce, traduzido ao português, significa comércio eletrônico, que consiste na compra e venda de artigos pela Internet, exercendo o papel de lojas virtuais. A Internet representa um meio de comunicação público e de fácil acesso, o que o torna um ambiente perfeito para a realização de negócios. Portanto, seus serviços devem incluir desde o compartilhamento de "informações de produtos e serviços até a realização de transações entre as partes que compõem o ambiente de negócio" (Albertin, 2000).

Correa et al (2006) afirma que criar e-commerces atualmente tem sido facilitado, através de alguns fatores, como poder ir se estabelecendo e testando o empreendimento aos poucos, sem precisar de uma estrutura já pronta. Ademais, "um empreendimento na internet tem praticamente as mesmas obrigações legais, como abertura de firma, contador e pagamento de tributos", porém, admite custos menores que uma empresa física.

\subsubsection{Fast fashion}

O fast fashion se diferencia do modelo tradicional de moda por admitir minicoleções de caráter semanal, poucas semanas para produção das peças, preços baixos e bastante competitivos, obtêm como orientação de tendências os próprios consumidores, resultando em menores riscos e maior lucratividade (Sebrae, 2014).

Tal modelo se caracteriza pela rapidez ao produzir os produtos de moda, de forma que, o termo traduzido ao português significa "moda rápida". Essa forma de produção acarreta novidades o tempo todo, porém os estoques são mais restritos, não contendo todas as numerações de tamanho. O fast fashion é conceituado pela absorção das tendências que serão bem concebidas pelos consumidores e rápida produção e distribuição das peças para venda. 


\section{Considerações finais}

Através da divisão dos dois grandes grupos, entre os modelos tradicionais e os modelos inovadores, conseguiu-se estabelecer pequenas definições dos modelos de negócios existentes na indústria da moda. Tal pesquisa deu-se como início aos estudos da área, delimitando um pequeno mapeamento, que pode ser utilizado a fim de originar novas pesquisas, aprofundando mais o conteúdo de cada setor.

Dentre os modelos tradicionais, foram apontadas as definições de criação (estilista), consultoria de moda, indústria/produção, indústria têxtil, jornalismo em moda, maisons (produtos de luxo), marketing em moda, modelista, produção de moda, varejo e vitrinista. Já os modelos inovadores abordam a assessoria de branding para empresa, blog de moda, customização, ecomoda, e-commerce e fast fashion. Tais modelos foram estabelecidos a fim de estipular as diferentes abordagens de cada um, diferenciando suas atuações no mercado de forma simplificada, permitindo aos estudantes distingui-los conforme as habilidades e conhecimentos que cada um desses modelos requer.

O que todos os modelos citados acima admitem em comum é a atuação em um mercado de trabalho cada vez mais competitivo, o que desencadeia à busca intensa por mudanças que promovam desempenhos melhores, como também a ampliação do índice de inovações e atratividade dos negócios. Eles têm como objetivo criar e dar o valor da marca aos clientes, com o intuito de agradá-lo e convencê-lo que é um bem necessário e deve ser adquirido.

\footnotetext{
Notas:

1 Empresas eletrônicas que exploram a comercialização de serviços ou produtos na Internet.

2 Disponível em:

<http://www.brasilprofissoes.com.br/profissoes/empreendedoras/empreendedoras/consultor-demoda\#> Acesso em 9 dezembro, 2014.

3 Disponível em: <http://www.abit.org.br/conteudo/links/publicacoes/cartilha_rtcc.pdf> Acesso em: 05 dez 2014.

4 Disponível em: <http://www.cce.puc-rio.br/sitecce/website/website.dll/folder?nCurso=producao-demoda\&nlnst=cce> Acesso em 4 dezembro, 2014

${ }^{5} \mathrm{Na}$ presente pesquisa será abordado o termo "branding", sinalizando o conjunto de estratégias para que uma marca se mantenha competitiva no seu nicho de mercado, na criação e/ou manutenção da mesma.
} 


\section{Referências}

ALBERTIN, Alberto Luiz. O comércio eletrônico evolui e consolida-se no mercado brasileiro. RAE - Revista de Administração de Empresas, v. 40, n. 4, p.94-102. São Paulo, SP. Out./Dez. 2000.

BERGAMO, Alexandre. 0 campo da moda. Rev. Antropol., v.41, n.2, São Paulo 1998.

BLYTHE, Mark. The Work of Art in the Age of Digital Reproduction: The Significance of the Creative Industries. Journal of Art \& Design Education, v. 20, Issue 2, p. 144-150, 2001.

CORREA, Rafael Felix; RUGONI, Tassiana Custódio; ALBUQUERQUE, Paulo; CAMOZZI, Clóvis; SOUZAE, Stefanie de Freitas; AlHARA, Simone. O impacto do ecommerce na sociedade. Revista de Informática Aplicada, v. II, n. 02, jul/dez. 2006.

COSTA, Marconi Freitas da; QUEIROZ, Neilza Oliveira de. Relevância da atmosfera da loja no varejo de moda. Semead, v. 5, n. 4, out./ dez. 2009, p.122-140.

FARIAS, Maria Luiza Almeida. O Design de Uma Geração: jovem e moda na Revista Claudia nos anos 1960/1970. Universidade Anhembi Morumbi, SP. 2011.

KELLER, Paulo Kernandes. O Estilista e a Indústria da Moda. ModaPalavra eperiódico, volume 3, n.6, jul-dez 2010, p. 19-36.

FIRJAN. Mapeamento da Indústria Criativa no Brasil. Disponível em: $<$ http://www.firjan.org.br/economiacriativa/pages/default.aspx>. Acesso em: 13/03/2015.

FRACARO, Fernanda Cereser; PAIVA, Juliana Teixeira de; ROSA, Lucas da; BASTOS, Talyta Duarte. Desenvolvimento do sistema de moda a partir dos estudos sobre economia criativa. Anais... $8^{\circ}$ Encontro de Extensão - Florianópolis, SC. UDESC, 2012.

GARCIA, J. A. C. Condições de trabalho e saúde dos trabalhadores da indústria do vestuário de Colatina. Dissertação (Mestrado em Saúde Coletiva) Universidade Federal do Espírito Santo. Espírito Santo, 2006.

GEARGEOURA, Lucien Jacques; MORIGUCHI, Stella Naomi. Formatação de lojassímbolo no varejo de luxo: tradição ou inovação? Das antigas maisons às modernas lojas-conceito e flagships. Anais... $6^{\circ}$ Congresso do Instituto Franco-Brasileiro de Administração de Empresas, IFBAE. 2011.

GOBBI, Maria Alice; BENETTI, Mariceia. A influência dos blogs de moda na decisão de compra do público feminino. Centro Universitário Metodista IPA. Porto Alegre, 2012.

HINERASKY, Daniela Aline. Jornalismo de moda: questionamentos da cena brasileira. Anais... Congressos Anuais da Intercom / Núcleo de Pesquisa Jornalismo. 2006. 
HORNBURG, Sigfrid; TUBINO, Dalvio Ferrari; LADEIRA, Natalia Emerich; THONERN, Ariane; RIFFEL, Larissa Fernanda. A programação da produção puxada pelo cliente: estudo de caso na indústria têxtil. Anais... XXVIII Encontro Nacional de Engenharia de Produção, 2008.

KHAUAJA, Daniela Motta Romeiro; MATTAR, Fauze Najib. Fatores de marketing na construção de marcas sólidas: estudo exploratório com marcas brasileiras. São Paulo: Atlas, 2006.

KACHBA, Yslene Rocha; HATAKEYAMA, Kazuo. Estratégias de inovação em APLs: viés para o desenvolvimento de produtos de moda. Produção, v. 23, n. 4, p. 751761, out./dez. 2013.

KOTLER, Philip. Marketing Management: Analysis, Planning, Implementation and Control. Canada: Prentice-Hall, 1989.

LEÃES, Sabrina Durgante. Marketing em moda. Universidade do Minho, Departamento de Engenharia Textil. 2008.

LUCIANO, Edimara Mezzomo. Consolidação de componentes de modelos de negócios para o comércio eletrônico de produtos virtuais. Porto Alegre: UFRGS, 2004.

LUINDÍA, Luíza Elayne Azevedo. Eco-marketing, desenvolvimento sustentável e Amazônia? Anais... XXIV Congresso Brasileiro da Comunicação, setembro 2001.

MATHARU, Gurmit. O que é design de moda? Porto Alegre: Bookman, 2011.

MELO, Luciana. As contribuições da Assessoria de Comunicação para o branding de produtos. Viçosa, MG. Monografia Curso de Comunicação Social/Jornalismo da UFV. 2009.

MENDONÇA, Carla. Jornalismo feminino, mulher e moda: uma relação histórica. Anais... 9॰ Encontro Nacional de História da Mídia, UFOP - Ouro Preto, MG. 2013.

PORTAL EDUCAÇÃO. A história da customização de roupas. Disponível em: <http://www.portaleducacao.com.br/moda/artigos/50771/a-historia-da-customizacaode-roupas $\geq$. Acesso em: 26/11/2014.

ROSA, Stefania. Alfaiataria: modelagem plana masculina. Brasilia: SENAC-DF, 2009.

SA, Ricardo Rocha Leal Gomes de; MARCONDES, Reynaldo Cavalheiro. O ponto de vendas de produtos de luxo da moda de vestuário feminino no Brasil. Cad. Ebape.Br, 2010, v.8, n.3, p. 514-534.

SANTOS, Simone. Impacto ambiental causado pela Indústria Têxtil. UFSC Engenharia de Produção e Sistemas - PPGEP - Centro Tecnológico - Trindade Florianópolis, SC.

SEBRAE. Desenhar não é o bastante para empreender em moda. Disponível em: <http://www.sebrae.com.br/Sebrae/Portal\%20Sebrae/UFs/PE/Anexos/perfil\%20de\% 20neg\%C3\%B3cios\%20de\%20moda.pdf>. Acesso em: 18/11/2014. 
SEBRAE. Fast fashion como estratégia de mercado. Disponível em: <http://www.sebrae2014.com.br/Sebrae/Sebrae\%202014/Boletins/1BO_Moda_Agost O_FastFashion.pdf>. Acesso em: 28/11/2014.

SEBRAE. Perfil de negócios da Moda: SEBRAE 2014. Disponível em: <http://www.sebrae.com.br/Sebrae/Portal\%20Sebrae/UFs/PE/Anexos/perfil\%20de\% 20neg\%C3\%B3cios\%20de\%20moda.pdf>. Acesso em: 14 out. 2014.

SEBRAE. Roupas em alta. Disponível em: <http://www.sebraesp.com.br/arquivos_site/noticias/revista_conexao/conexao_39>. Acesso em: 11/11/2014.

TAVERNARI, Mariana Della Dea; MURAKAMI, Mariane Harumi. O gênero dos Fashion Blogs: representações e autenticidades da moda e do feminino. Rumores, ano 6, n. 2, p. 85-106, julho/dezembro 2012. 